
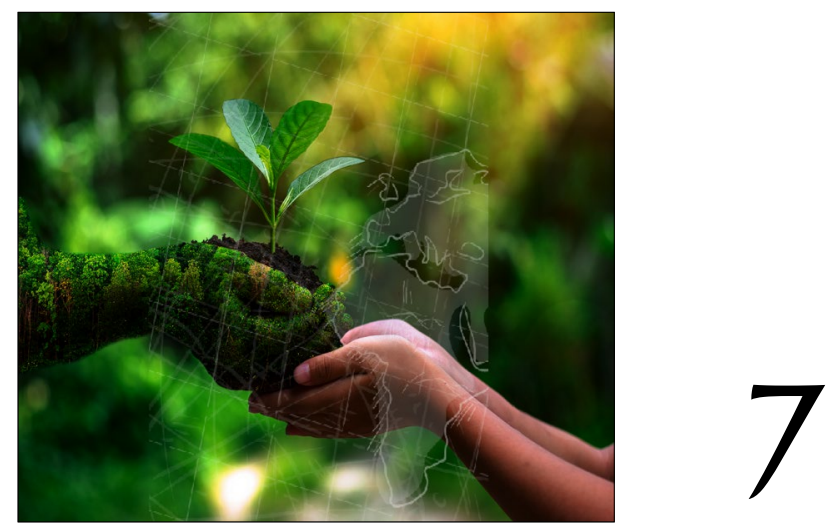

\title{
DISTRIBUTED RENEWABLE ECONOMY FOR AFRICA AS A BASIS FOR WELLBEING ECONOMY DEVELOPMENT
}

\author{
Desta Mebratu
}

\section{Introduction}

The global economy has registered a tremendous growth rate in terms of gross domestic product (GDP) over the last few decades. This has resulted in significant improvement of human development in different parts of the world, and more particularly in developed countries and transition economies. However, more than two billion people are still deprived of the basic necessities and living in poverty. On top of this, the foundation for the global economy has been shaken over the last decades by a confluence of multiple economic, environmental and social challenges. In his book, Shaping the Fourth Industrial Revolution, the founder of the World Economic Forum (WEF) Klaus Schwab writes: 'The world is at a crossroads and the social and political systems that have lifted millions out of poverty and shaped our national and global policies for half a century are failing us' (Schwab, 2018:vii).

The existing situation is expected to be further aggravated with the projected increase of the global population to over nine billion by 2050. Addressing these 
challenges will require a fundamental transformation of the current global production and consumption structure. Achieving incremental efficiency gains in all socio-economic activities is a necessary ongoing process of every society. However, promoting systems innovation at all levels of society is fundamental to address existing and emerging socio-economic and socio-ecological challenges adequately.

As noted by Swilling and Annecke (2012), various transitions are already underway in response to resource depletion and adverse environmental impacts, but something fundamental must change in the way that economies relate to their environments. Despite the notable progress made, there is still strong inertia that hinders the progress towards a transformational change which is urgently needed. Social transformation is inherently a complex process that involves the introduction of new thinking, products, processes and organisations that profoundly change the basic routines, resource and authority flow and beliefs of the social system. Transformational moments require challenging widely accepted logic, practices and relationships. This becomes even more complex in an increasingly globalised but fractured world as we are in today. However, these transformational moments would also provide new opportunities that could be utilised as a driver for change. Today, society is standing at a crossroad where the transition to an inclusive, lowcarbon and resource-efficient economy is no more a choice but a global imperative. Africa is the region that will face significant adverse impacts from the global environmental challenges such as climate change. In addition to addressing the environmental challenges, African countries face other key challenges that need to be addressed, such as creating jobs for its increasing percentage of young population and eradicating poverty There is also the challenge of reducing the adverse impacts of emerging technologies, which have exponential implications, while making the best out of the opportunities they provide.

This chapter highlights some of the key drivers and opportunities which African countries need to recognise and take advantage of in developing their economies. It specifically recommends the promotion of distributed renewable economy planning in regional and local development to achieve the Sustainable Development Goals and meet the aspiration of Agenda 2063. It also highlights some of the key steps and planning tools that could be used in planning for a distributed renewable economy.

\section{Social transformation and its transition elements}

In general, the concept of societal transformation in the social sciences refers to the change in society's systemic characteristics. According to Nikolai Genov (1999), 
this incorporates the replacement of existing parameters of a societal system, including technological, economic, political and cultural restructuring. More specifically:

Such a process influences productive infrastructure which can bring about new technological changes and new patterns of participation in the division of labour. Historically, this has meant alteration of the requirements for information flows and technologies.

Secondly, new structures of economic organisation are developing. This may imply a change in ownership rights, as well as in investments, production, distribution and supply.

Thirdly, the distribution and use of political power take qualitatively different forms. This involves changes in the structure and performance of state institutions and other bodies of decision-making and control.

Finally, a society's value-normative system can change, often in a way that allows the emergence and stabilisation of pluralist institutions (Genov, 1999).

Swilling and Annecke (2012) noted that besides the unviability of the old regime, which manifests itself through different forms of crisis, there have to be conscious and purposive innovations that create pathways to a new order. In this section, we look at some of the significant shifts and changes that happened over centuries and defined the transformation path taken by societies.

\section{Social transformation as a cumulative process}

Succession and mobility of plants and animals, as an essential element of the selfregulation mechanism of the biotic system, played a significant role in the coevolution of the natural and social systems. As an integral part of the natural system, more particularly the animal kingdom, mobility governed by ecological factors has patterned the dominant lifestyle of humanity for millennia (Mebratu, 1998). The natural system has been the primary source that provided all the essential resource inputs required for all socio-economic functions. Fischer-Kowalski and Harbel (2007) identify three major socio-ecological regimes in human history:

The hunter-gatherer socio-ecological regime that existed for at least 100000 years before the agricultural revolution that took place some 13000 years ago.

$\square$ The agrarian socio-ecological regime that existed until the industrial revolution nearly 250 years ago.

The industrial socio-ecological regime that begins in the 1770 s and which is currently dominant in the global economy. 
About 8000 years ago, after aeons of slow accumulation, the human population reached an enormous number of about ten million people (Meadows, Meadows \& Randers, 1992). These people lived as nomadic hunter-gatherers, but their increasing numbers began to create ecological scarcity around them. To resolve the problem of dwindling wild resources, some of them intensified their migratory lifestyles, while others started to domesticate animals and cultivate plants resulting in a sedentary lifestyle. Just by staying in one place, the proto-farmers altered the face of the planet and the thought of humankind in ways they could never have foreseen (Meadows et al., 1992).

As a result of this change in human behaviour, history from $3000 \mathrm{BC}$ till the advent of the industrial revolution witnessed the development of more advanced agriculture, increasingly multiple social divisions of labour and means of exploitation. This included the creation of exclusively masculine symbols of divinity and the subjugation of women by patriarchal control over their reproductive and sexual status (Gottlieb, 1996). The agricultural transformation, as a successful response to wildlife scarcity faced by the hunter-gatherer society, resulted in slow population growth from about 10 million to about 800 million by 1750 (Meadows et al., 1992). This created new scarcities and social conflict, especially in land and energy, and led to the industrial revolution.

The industrial revolution, which started in the UK with the development of the textile industry, is said to have passed through three distinct stages of industrial revolutions (Schwab, 2018). The first industrial revolution started with the mechanisation of spinning and weaving in the textile industry. The substitution of abundant coal for vanishing biomass resulting in the introduction of the steam engine. This led to new developments in other manufacturing sectors including steel manufacturing and transportation sector. A new wave of interrelated technologies that came between 1870 to 1930 further enhanced the growth made during the first industrial revolution and created new opportunities. The technologies included new communication infrastructure driven by the power of electricity, new transportation possibilities driven by internal combustion engines, and the production of new materials, such as thermoplastics, as a result of the development in chemicals processing. The revolutionary breakthroughs that were registered in the area of digital computing and information theory since the 1950s provided the foundation for the third stage of the industrial revolution. These three stages of the industrial revolution transformed the way human beings create value, and the world was changed by the co-evolution of technologies, political systems and social institutions.

The unprecedented economic growth registered through the agricultural transformation and the successive stages of the industrial revolution led to new sets 
of environmental scarcities and crises of a global proportion. These scarcities grew exponentially with the fast pace of industrialisation and globalisation that was registered during the second half of the twentieth century. The globalisation of the twentieth century did not only globalise national economies. It also globalised environment pollution and degradation which remained local for millennia resulting in global challenges such as climate change. The exponential increase in inequality between and within countries is another significant social outcome of unbridled globalisation. As reported by Vázquez Pimentel, Ayma and Lawson (2018) in an Oxfam Briefing Paper, the 26 wealthiest people on earth in 2018 had the same net worth as the poorest half of the world's population, some 3.8 billion people. These challenges are expected to be further compounded with the alarming rate of population growth that is projected to be over nine billion by 2050. In a nutshell, humanity is currently faced with a confluence of economic, social, and environmental challenges that would require a significant social transformation of equal proportion to the agricultural and industrial revolution. Africa, as a developing region, may swim through or get drowned by this transformational change depending on how it deals with the critical transition elements and drivers in the coming decades.

\section{The transition elements}

Moments of major social transformations are characterised by the dynamic interaction between the socio-ecological and socio-economic systems. These, in turn, are shaped by (i) how useful information or knowledge is processed and structured, (ii) which kind of energy systems is used as the primary driver, and (iii) how the production system is organised by using the first two as primary inputs. These factors have determined the key features of the agricultural and industrial transformations and will also determine the sustainability transformation of the twenty-first century.

Table 7.1 presents a comparative analysis of the key drivers and features of the transitions under the agricultural, industrial and sustainability transformation.

Table 7.1 Key elements of major socio-economic transformations

\begin{tabular}{|l|l|l|l|}
\hline Principle dimensions & $\begin{array}{l}\text { Knowledge } \\
\text { systems }\end{array}$ & $\begin{array}{l}\text { Dominant } \\
\text { energy drivers }\end{array}$ & $\begin{array}{l}\text { Production } \\
\text { systems }\end{array}$ \\
\hline Agricultural transformation & Philosophy and religion & Bio-energy & Subsistence production \\
\hline Industrial transformation & Reductionist science & Non-renewables & Mass production \\
\hline Sustainability transformation & Systems thinking & Renewables & Distributed production \\
\hline
\end{tabular}

The following subsections present a more detailed discussion on the key features of the transitions that were recorded in the three principal dimensions shown in Table 7.1. 


\section{The knowledge transition}

The transition that should happen in our knowledge system is one of the critical prerequisites for a successful transformational process. Philosophy, as the earliest form of knowledge acquisition, and religions, by way of shaping human conscience, played a significant role in determining the path of the agricultural transformation and consolidating its gains. The industrial revolution paved the way for substantial progress made in science and technology. The classic metaphysical transplant from Newtonian physics to social reality was achieved by Adam Smith under which gravity became the market, molecules became individuals, and the constancy (and reversibility) of time became value (Swilling \& Annecke, 2012). At the same time, the reductionist idea that advocates nature as a great machine which can be understood by studying the parts has become dominant through the whole of modern thought and culture. Finding a pattern of thinking about social reality which was similar to the pattern set by the natural resources gradually became the primary intellectual ambition of social scientists. This dominant thinking led to the unprecedented speed and magnitude of economic development, particularly over the last century.

However, the mismatch problem that arises from the description of a grey world with black-white scientific truth increasingly became the source of the limitation of the dominant knowledge model of the last century. As Kosko (1994) suggests, the bivalence of modern science ignores or denies or whitewashes, and black washes grey truth. On the contrary, the multivalent view says that almost all truth is grey and partial truth and it allows mathematical truths to remain black or white as extreme cases of grey. This led to the evolution of the holistic view, which asserts that natural wholes are always composed of parts under which the synthesis affects and determines the parts and, therefore, reciprocally influence and determine each other (Smuts, 1993). Under such thinking, the whole is much more than the summation of the parts.

Although nobody can deny the enormous positive effect of science and technology, it is equally true that science and engineering have been unable to keep pace with the second-order effects produced by the first-order victories (Weinberg, 1975). Numerous institutional and individual attempts were made to understand the impacts of these second-order effects and cope up with prescriptive solutions. However, these efforts were not able to adequately address the multidimensional challenges that are complex due to the inherent limitations in their epistemological foundations (Mebratu, 2000). The key determinant for our success in this process is the progress we make in developing a new framework of knowledge and thinking. 
The initial response to the increasing level of the environmental crisis naturally originated within the entrenched domain of the different disciplinary sciences (Mebratu, 1998). However, the inherent limitations of these disciplinary sciences were soon recognised by the scientific community. This led to the proliferation of multidisciplinary and interdisciplinary approaches that led to various incremental progress in different fields. Nevertheless, as noted by Leroy (1997), the interdisciplinary approach primarily became a question of the transfer and integration of methods rather than the forging of substantive theories. In terms of the solution, the dominant mechanistic nature of the inclusion process results in solutions of detailed complexity, which diverts attention away from systemic causes by focusing on symptoms (Ziegler, 1997).

Recognition of these limitations gave rise to what is broadly known as 'systems thinking' which became increasingly used since the 1970s in different fields. According to Kelvin Campbell (2018), there are three common organising principles of complex adaptive systems. Firstly, self-organising systems produce intelligence only when they can process the diversity of knowledge that resides within the entire system. Secondly, counterintuitive to conventional wisdom, which believes in a comprehensive set of rules and regulation to achieve effectiveness, complex adaptive systems leave the responsibility for control and coordination with each of the individual members. Thirdly, order is not preordained before work begins but instead emerges through an interactive learning process.

A key challenge in adopting an approach of doing science with society is to develop solution-oriented, or transformative transdisciplinary research approaches that are capable of not only explaining and understanding the complex societal challenges currently being faced in the world, but also of changing or transforming these challenges (Breda \& Swilling, 2018; Miller et al., 2014; Scholz, 2011; Seidl et al., 2013; Stauffacher, Walter, Lang, Wiek \& Scholz, 2006; Wiek \& Lang, 2016). The transdisciplinary field started to emerge from the increasing recognition of the urgent need to generate solutions based on understanding dynamic complexity (Mebratu, 2000).

The systems approach is based on the recognition that all systems are in a state of disequilibrium following an irreversible path of development and sustaining their systemic function through successive adaptation is their main raison d'être (Mebratu, 2000). Such an approach focuses on defining the basic principles that map out the evolutionary paths of any system within a given possibility domain rather than generating prescriptive solutions based on applying broad principles across socio-economic systems. This provides a sound basis for hybridising and cross-fertilising across knowledge systems, including indigenous knowledge systems, and promoting social innovation at the local level. 
Table 7.2 shows some key features of conventional and transformational development.

Table 7.2 Features of conventional and transformational development

\begin{tabular}{|l|l|l|}
\hline Key features & Conventional & Transformational \\
\hline Knowledge system & Reductionist and mono-disciplinary & Systems thinking and transdisciplinary \\
\hline Innovation regimes & Technological regimes & Socio-technological regimes \\
\hline Social outcome & Power consolidation and increased inequality & Distributive and enhanced inclusiveness \\
\hline
\end{tabular}

As shown in Table 7.2, the specific knowledge system that is dominant will determine the nature of the innovation regimes and the respective social outcomes. Hence, the transition in our knowledge system is one of the fundamental prerequisites for addressing the confluence of challenges caused by the conventional development paradigm. The accumulation and evolution of knowledge through successive stages of transitions is an inherent part of social transformation processes. The challenges facing humanity today require a new framework of thinking that is guided by transdisciplinary methodologies which systematically integrate and deploy all the relevant existing knowledge through systems thinking.

\section{The energy transition}

Throughout human history, energy has been at the centre of every major social transition and transformation. The discovery of fire represented a significant turning point in the differentiation of human beings from the animal kingdom in the form of production and the use of tools. This was followed by the discovery and use of bioenergy as a result of domestication and use of animals for farming and domestic purposes. The subsequent development of watermills and windmills played a significant role in the agricultural transformation of the first and second millennia. The discovery of coal and the subsequent invention of the steam engine laid the foundation for the industrial revolution of the eighteenth and nineteenth centuries. Subsequently, the discovery and extensive utilisation of petroleum played a central role in the development of chemicals and material sciences as a basis for diversified products and as a key driver for new modes of transportation and communications.

The transition from renewable to non-renewable energy resource as the dominant energy provider of national economies also represented a significant turning point in society's relationship with the natural environment. The unregulated discharge of greenhouse gases (GHGs) into the atmosphere, which resulted in the global challenge of climate change, led to the systemic deposition of various chemical pollutants in the natural environment. This has fundamentally changed the scale and scope of impact of human activity on the environment making it of a global proportion. Hence addressing the environmental challenges of today would require a transition of a global proportion in our energy systems as confirmed with 
the Paris Agreement on Climate Change and series of scientific reports from the International Panel on Climate change (IPCC).

Decarbonising the global economy through a rapid transition of our energy systems to a renewable energy resource basis is of vital importance in light of the urgency of addressing the challenges of climate changes. This would require shifting our energy production focus from the exploitation of concentrated energy potential, which is mostly non-renewable and limited, to the harnessing of the abundant and renewable diffused energy potentials within our planetary system. Besides the global necessity of making such a transition, African countries can enjoy the following additional developmental benefits from such a transition to renewable energy systems:

According to the International Renewable Energy Agency (IRENA), the continent's biomass, geothermal, hydropower, solar and wind energy resources are among the best in the world (IRENA, 2015). Given the abundant potential the region has, renewables can play a transformative role in the African energy mix and its socio-economic development.

About 600 million people in Africa do not have access to electricity, and approximately 730 million people rely on traditional uses of biomass (International Energy Agency [IEA], 2014). Expanding and ensuring energy access for the majority of the population in Africa is at the centre of achieving distributional energy justice and eradicating poverty in Africa.

The distributed nature of renewable energy resources combined with widely dispersed settlement patterns of the bulk of the population in the region makes the development of distributed energy systems more appropriate for the region.

The development of local economic networks driven by renewable energy provides the foundation for developing distributed economic systems that add value to locally available renewable resources and creates jobs that are desperately needed in the region.

Africa is one of the regions with significant renewable energy potential, however, a very high proportion of its population suffer from energy poverty. Recent progress made in renewable energy technologies and the favourable policy environment at the global and regional level provides a unique opportunity for the energy transition in Africa. This transition could promote a significant level of distributive justice if due consideration is given to the right mix of grid- and off-grid based renewable energy systems. It could also promote broader socio-economic justice if the planning and implementation of renewable energy development are fully integrated with the development of sustainable local economies that create decent jobs and provide sustainable livelihoods through value addition to local resources. 


\section{Transition in production systems}

Production is the fundamental factor that separates humankind from the animal kingdom. As such, change that happens in production systems is at the centre of all major social transformation processes. The concept of economy of scale as defined by Adam Smith, with cost per unit of output generally decreasing with increasing scale, has been the significant driver for the development of megaproduction and distribution systems. Some political economists have challenged this dominant notion of economy of scale for decades. Theodore Roszak (1989) noted that there were many proponents of subterranean tradition or organic and de-centralist economics who insisted that the scale of the organisation must be treated as an independent and primary problem. However, he noted that it would be no exaggeration to call Schumacher the Keynes of post-industrial society. McClaughry (1989) noted that Schumacher's book Small is Beautiful published in 1989 provided a new sense of hope to a world that is faced with widening spectre of global pollution, resource-exhaustion, corporate concentration and the corresponding diminution of individual liberties.

Ayres (1994) defines an economy as an information processing system and identifies three kinds of information. These are thermodynamic information, associated with the chemical composition; morphological information, associated with shape, form and structure; and symbolic information, associated with control process and knowledge. He further argues that labour skills, capital and technology are more or less embodied or condensed forms of information of a production system. Based on this, one can conclude that all production systems are ultimately systems that process raw material, energy and information into useful products (both goods and services) consumed by society. Industrial development during the twentieth century had been mainly driven by various innovations that resulted in better management of the dynamics between the thermodynamic, morphological and symbolic information of production systems.

Considering that the thermodynamic content of any production is an input provided by the natural environment, the morphological and symbolic information become the fundamental factors that determine the distinction in production systems. As a result, the level of inventions and innovations that are witnessed at each stage of the major social transformations were a function of how the morphological and symbolic information was processed and utilised. The critical function and role of information in economic systems have taken new dimensions and proportions with the unprecedented development witnessed in the field of information and communication technology in the last couple of decades. This ranges from changing the speed and nature of financial flows, which is another form of information flow, to giving rise to new products and industrial operations. 
The continued digitisation of the global economy is expected to result in fundamental changes in the design and development of production systems of the twenty-first century.

The transition in production systems starts with the evolution of new production systems within the old as a result of the germination of the seeds of change within the old production system. This provides the basis for the evolution of new production and consumption relationships that are necessitated by the fundamental socio-economic and socio-ecological drivers for change. The seeds for change concerning production systems of the twenty-first century are already sprouting in different sectors and different parts of the world. However, there are some fundamental shifts required for these changes to lead to inclusive, lowcarbon and resource-efficient societies. In this context, the transition in production systems further includes broad-based transitional changes that should happen in the areas of the economy of scale and related energy and information systems.

One recent application of such an approach is the framing of the fourth industrial revolution by Klaus Schwab, who proposes that the 'Fourth Industrial Revolution is a new chapter in human development, on par with the last three stages of industrial revolution, and once again driven by the increasing availability and interaction of a set of extraordinary technologies' Schwab (2018:7). However, the possible impacts and benefits of the disruptive technologies of the fourth industrial revolution will mostly depend on who would have control over the use of these technologies.

Table 7.3 shows the possible outcomes of some of the key disruptive technologies depending on whether we use them for the conventional outcome of consolidating dominance by the few or for transformational outcomes that will lead to more inclusive and efficient economies.

Table 7.3 Possible socio-economic outcomes of emerging technologies

\begin{tabular}{|l|l|l|l|}
\hline $\begin{array}{l}\text { Emerging } \\
\text { technologies }\end{array}$ & $\begin{array}{l}\text { Application } \\
\text { regimes }\end{array}$ & $\begin{array}{l}\text { Conventional } \\
\text { outcomes }\end{array}$ & $\begin{array}{l}\text { Transformational } \\
\text { outcomes }\end{array}$ \\
\hline $\begin{array}{l}\text { Artificial } \\
\text { intelligence }\end{array}$ & $\begin{array}{l}\text { Digitisation and } \\
\text { robotisation }\end{array}$ & $\begin{array}{l}\text { Consolidation of mass production } \\
\text { and consumption resulting } \\
\text { in substantial job losses and } \\
\text { concentration of wealth }\end{array}$ & $\begin{array}{l}\text { Promotion of distributed } \\
\text { production aimed at improved } \\
\text { productivity and empowerment of } \\
\text { local communities }\end{array}$ \\
\hline $\begin{array}{l}\text { Blockchain } \\
\text { technologies }\end{array}$ & $\begin{array}{l}\text { Distributed ledger } \\
\text { of transaction }\end{array}$ & $\begin{array}{l}\text { Speculative capital accumulation } \\
\text { through crypto-currencies }\end{array}$ & $\begin{array}{l}\text { Promotion of distributed economy } \\
\text { via efficient supply chain networks } \\
\text { and local digital currency }\end{array}$ \\
\hline Biotechnologies & $\begin{array}{l}\text { Genetic } \\
\text { engineering }\end{array}$ & $\begin{array}{l}\text { A narrow application aimed at } \\
\text { power control and consolidation in } \\
\text { the name of human wellbeing }\end{array}$ & $\begin{array}{l}\text { Systemic applications aimed at } \\
\text { the improvement of human and } \\
\text { ecosystem wellbeing }\end{array}$ \\
\hline
\end{tabular}

The battle is already on between the conventional groups that are bent on making the maximum profit and power consolidation out of the emerging disruptive technologies and the advocates for the transformational utility of these technologies 
for the broader and higher benefit to humanity. Schwab outlines the following four fundamental principles that are particularly useful in defining a new leadership mindset that ensures a more favourable outcome from the fourth industrial revolution (Schwab, 2018):

Systems not technologies: It is essential to focus on systems that deliver wellbeing rather than being tempted to focus on technologies themselves. With the right engagement of all stakeholders, new technologies can enable betterperforming systems to be put in place, while the absence of them could make the existing systems worse.

Empowering not determining: It is imperative to value human decisionmaking and agency and design systems that harness new technologies to give people more choice, opportunities, freedom and control over their lives.

By design not by default: Society should not resign itself to the inevitability of default options. Design thinking, guided by human-centred design, as well as systems-thinking approaches can help the world to appreciate how new technologies may shift systems into new configurations.

Values as a feature, not a bug: We should recognise that all technologies implicitly have values baked in them from the initial idea to how they are developed and deployed and hence we need to debate values at all stages of innovation rather than reacting after the damage has been caused.

In general, the twenty-first century will be registered as the century of the most significant social transformation in human history. This transformation is of global proportion and would have a significant immediate impact on Africa's opportunity to develop its economy. As was shown in the chapter on leapfrogging, Africa has a unique opportunity to be a significant beneficiary of this transformation. However, for Africa to reduce the adverse impact of this transformation on its people and maximise its benefit, it has to come out of its passive recipient status and prepare itself to be an active player of this transformation by seizing the available opportunities. The emerging disruptive technologies, which are inherently distributive, provide excellent opportunities for the economic empowerment of people provided that these technologies are utilised innovatively. One of the strategic approaches for this is to commit to an inclusive, low-carbon and resourceefficient bottom-up economic development process through the promotion of a distributed renewable economy, which is discussed in the following section.

\section{Distributed renewable economy}

As it was presented in the other chapters of this book, given their early stages of development, African countries have great opportunities to build a more sustainable 
socio-economic infrastructure that facilitate the transition to inclusive, low-carbon and resource-efficient economies. Such a transition could only be successful if it is complemented with a bottom-up process of developing distributed economy networks that create productive and decent jobs and secure economic livelihood to local communities. The following subsection highlights the conceptual and practical basis for the development of a distributed renewable economy.

\section{The conceptual basis of a distributed economy}

The discussion on distributed economy as a strategy that guides industrial development towards a more sustainable development path started towards the end of the twentieth century and the beginning of the twenty-first century. The discussion was mainly triggered by the recognition of the limitations of technical innovations in the field of pollution prevention and cleaner production in addressing the growing resource and environmental challenges. It also recognised the need to question the purpose and structure of the dominant production systems and ultimately transform them. According to Johansson, Kisch and Mirata (2005), distributed economy promotes economies of scale through networking, and offers an approach by which different strategies can be pursued in different regions and similar or complementary development schemes can be brought together into networks providing the advantages of scale without the drawbacks of inflexibility. It also optimises resource flows that take place within and across regional boundaries through the development of regions where a diverse range of activities are organised in the form of small-scale, flexible units that are synergistically connected and prioritise quality in their production. Under such circumstances, industrial symbiosis becomes more than mere coexistence.

The International Institute for Industrial Environmental Economics noted that the dominant economic system of today has mostly been driven by the concept of 'economies of scale' that is based on the principle that production costs per unit output decline as output increases, thus making larger industrial production more attractive and profitable (Van den Dool et al., 2009). The belief in this approach has created an industrial production system largely dominated by mass production and concentrated industrial cores. However, the 'economies of scale' that is widely applied in the dominant economic model is at best partial and static and thereby inefficient. According to Van den Dool et al., the concept of distributed economy does not go against the principle of economies of scale. On the contrary, it argues that there are many cases where distributed production systems would meet the requirement for economies of scale more holistically and dynamically provided that the production costs take into account all environmental and social costs and benefits associated with it (Van den Dool et al., 2009). 
Another major limitation of the conventional economic model is its assertion of the direct correlation between economic growth and wellbeing improvement. The persistence of poverty and widening inequality both within and between countries despite the fastest global economic growth pose significant barriers to the advancement of human wellbeing. It has been claimed for decades that economic growth and technological innovation offer the best possibilities to overcome these barriers. However, this seems to have failed, resulting in increasing public discontent and disappointment in all parts of the world. Furthermore, the dominant ways of measuring economic progress in the form of growth of GDP are not only misleading but are also misguiding and ineffective, to say the least (Lorenzo, 2017). As pointed out by Ayres (1999), the major part of statistical growth amounts to running faster and faster to stay in the same place - wheel-spinning - rather than actual wealth creation. In this context, Johansson et al. (2005) suggest the following major areas of concern that distributed economy attempts to address:

Wealth creation for a larger number of people: The purpose of economic development is to allow people to lead a meaningful life under which many basic needs have to be fulfilled and options for individual choices are provided.

Heterarchies and open innovations: A centralised and hierarchical production system is poorly suited for coping with this new era of open innovation. With distributed economy, we are talking about heterarchies under which knowledge is distributed and the organisation of diversity becomes crucial.

Flexible and small-scale production systems: Flexible and small-scale production systems have inherent advantages to receive relevant market signals and to devise and implement innovative solutions that satisfy the dynamically changing demands. This will be increasingly important and determinant for survival in future economies.

Symbiotic relationships: Real value is to appreciate the importance of both competitive and non-competitive processes and find a balance between the two. The interaction between different entities combines in such a way that the system as a whole performs better and is more robust than the performance of the individual entity.

Diversity as a prerequisite: Distributed economies have a high performance, not because of the competitive nature of individuals or even because of the direct cooperation but because of the diverse elements in the economy.

New producer-consumer relationships: Today, relatively small actors can have both local and global presence at an affordable cost. In particular, information technology has provided us with the possibility of having a global presence and satisfying the need of being large or dominant. 
Social and ecological capital as an advantage: In distributed economies, there is a clear emphasis on using social and ecological capital as an advantage. This is a form of a natural asset that can deliver unique values in a unique mix if it is wisely designed and utilised.

A renewed balance of scale: Distributed economies does not advocate abandoning large-scale production systems as a whole. On the contrary, there will undoubtedly be a need for efficient ways of producing commodities and bulk goods. However, new forms of symbiosis and coexistence could bring about benefits to both systems.

The notion of distributed economies generally promotes small-scale, flexible networks of local socio-economic actors using local resources according to local needs in the spirit of sustainable development (Kohtala, 2015). Besides its direct economic and environmental benefits, it provides a robust socio-economic basis for the empowerment of women and the broad participation of local communities in development management. It also provides a fertile ground for socio-technical innovations that are driven by local needs and conditions. Thus, the promotion of networks of local economies that create more jobs and add more value to local economies need to be at the centre of promoting sustainable development in Africa.

\section{Technological drivers for a distributed economy}

As noted in the preceding chapter, technological invention and innovation have been central to all major socio-economic transformations that are recorded in human history. This includes the agricultural revolution and the various stages of industrial revolutions. However, the impact of technological innovations of the twenty-first century that are mainly driven by digitisation and the transition in our energy and production systems are of exponential proportion. Some of these are referred to as exponential technologies owing to their significantly higher outcome and impacts compared to their conventional counterparts. In the context of this chapter, three major technological innovations determine the path of social transformation in the twenty-first century. These are:

the digitisation of the global economy;

the development of renewable energy technologies; and

the expansion of distributed manufacturing systems.

\section{The digitisation of the global economy}

The increasing digitisation of the global economy as a result of exponential development in the field of information and communication technology is one of the most defining drivers of the global economy in the twenty-first century. Most of the 
key technologies behind the fourth industrial revolution (Industry 4.0), including artificial intelligence, robotics, additive manufacturing and augmented reality, are driven by the innovation, development and the application of information and communication technology (ICT) for digital innovation. The foundation for most of the development in the ICT sector, including the development of the internet and world-wide-web, is driven by the concept of distributed systems. This concept is applied widely in the ICT field. The term 'distributed' had its roots in computing and communication networks when a more robust network that has distributed nodes rather than centralising hubs or switches was developed (Baran, 1964).

Schwab identified two categories of technologies that would determine the nature of the fourth industrial revolution. The first group of technologies are those technologies that are aimed at extending the benefits from the digital revolution of the third industrial revolution that brought us general computing, software development, personal computers and connectivity. These include new computing technologies, blockchain and distributed ledger technologies and the internet of things (IoT). The second group of technologies are the technologies that provide the materials of our living environment and interact with both industrial and social spaces using the digital infrastructure of the twenty-first century as a foundation. These include artificial intelligence (AI) and robotics, advanced materials and additive manufacturing (Schwab, 2018).

The distributive nature of the development over the last couple of decades in ICT has led to improving efficiency and enhancing the empowerment of individuals. The enormous power of influence that has been created by the widespread use of social media with its attendant social hazard is a clear testimony of this distributive power. The transition to the digital economy is expected to come with a mix of challenges and opportunities. The success of every nation in the twenty-first century will depend largely on its ability to effectively manage the challenges, harness the opportunities and master the impact of this transition.

\section{Distributed renewable energy systems}

Another technological revolution is taking place between energy supply and demand, powered by information, computing, communications and control technologies. This is transforming the ability to manage a dynamic electricity system that integrates decentralised and variable clean, renewable supply with demand (Cooper, 2016). The techno-economic viability of renewable energy options has registered significant progress over the last decade owing to the favourable policy and investment conditions created at the global, regional and national levels. This ranges from various forms of policy and regulatory reforms at regional and national levels which are favourable for renewable energy development to direct and indirect economic incentives provided by national governments. 
Most African rural communities are characterised by low population densities and dispersed settlement patterns, resulting in high connection costs. Smaller hybrid energy plants closer to the end-user consisting of multiple energy sources are emerging as an alternative to large energy and distribution power plants with competitive price and improved reliability and security (Raji \& Kahn, 2012). Distributed energy resources could be both conventional and nonconventional energy sources connected to the primary feeder or secondary feeder of a distribution system (Alanne \& Saari, 2006). The International Renewable Energy Agency describes Africa as the continent of opportunity because of the significant potential it has both in terms of the renewable energy resource it has and the existing energy gap that needs to be addressed (IRENA, 2013).

Distributed renewable energy (DRE) systems offer unprecedented opportunities to accelerate the transition to modern energy services in remote and rural areas and also provide various co-benefits. According to the Renewables 2017 Global Status Report (REN21, 2017), the major benefits include: (i) cost savings when compared to the grid in many markets; (ii) fuel availability and/or stability and predictability of prices; (iii) modularity, flexibility and rapid construction times; (iv) faster technological learning curves and rates of improvement compared to fossil fuels; (v) enhanced reliability and resilience; (vi) improved health through reductions in indoor air pollution; (vii) contribution to climate change mitigation; (viii) reductions in deforestation and environmental degradation; (ix) positive effects on women's empowerment, and (x) reductions of poverty among vulnerable groups (REN21, 2017:97). The report also maintains that 'the old paradigm of energy access through grid extension alone is becoming obsolete as bottom-up customer demand is motivating hundreds of millions of households to generate their own modern energy services through off-grid units or community-scale mini-grids' (REN21, 2017:24).

As mentioned previously, Africa has a substantial potential for renewable energy, but at the same time, a large percentage of its population suffers from energy poverty. If current African development trends continue, almost 600 million people in rural areas will still lack access to electricity in 2030, and an even more significant number will require access to clean cooking facilities. According to the regional decomposition analysis carried out by Mundaca, Markandya and Nørgaard (2013), Africa appears to be the only region that showed signs of grabbing the low-carbon economy opportunity. Besides facilitating energy access, the development of local economic networks driven by renewable energy provides the foundation for developing distributed economic systems that are based on the efficient utilisation of locally-available renewable resources and hence leapfrogging to the low-carbon economy. However, realising this potential would require taking 
some critical measures aimed at creating the necessary framework for the effective deployment of the required physical and institutional infrastructure.

Recent progress made in renewable energy technologies and the favourable policy environment at the global and regional levels provides unique opportunities for the energy transition in Africa. This transition could promote a significant level of distributive justice if due consideration is given to the right mix of grid- and off-grid based renewable energy systems. It could also promote broader socio-economic justice if the planning and implementation of renewable energy development are fully integrated with the development of sustainable local economies that create decent jobs and provide sustainable livelihoods through value addition to local resources. All of the above major drivers indicate that we are at a moment of a significant social transformation process that will require all countries to revisit their development planning process fundamentally. The promotion of distributed renewable economy as a development planning tool is one key element of this transition that responds to all the major drivers highlighted above.

\section{Distributed manufacturing systems}

The notion of distributed production is a conceptualisation of a shift in consumption and production patterns away from the conventional mass production paradigm with its centralising tendencies. This transition also poses a challenge to the notion of having strict intellectual property (IP) regimes as the foundation for technological innovation. Based on empirical data from the United States, Dafermos (2015) points out that the dramatic increase in the number of patents registered in the United States from 1973 to 2010 has not been paralleled by an increase in productivity or technological innovation. On the contrary, based on two case studies, he illustrates how innovation in the twenty-first century thrives on openness and free sharing of knowledge and presents an alternative model of economic and technological development enabled by inclusive IP regimes founded on the open knowledge commons. Bauwens and Kostakis (2015) emphasise the need for recomposing productive infrastructures for commons-oriented development.

Distributed production is enabled especially by advances in digital manufacturing technologies and the internet and is often referred to as distributed manufacturing (DM) or personal manufacturing. However, distributed manufacturing goes beyond the introduction of intelligent and autonomous systems that are driven by digitisation and smart machines. It also includes new societal considerations of a highly participative form of decentralised manufacturing that requires participation across the manufacturing value chains, including end-users, from design to potential production (Srai et al., 2016). Furthermore, DM entails a 
deviation from conventional mass production, not only in terms of scale and location but also in terms of the consumer-producer relationships (Kohtala, 2015). The implication here is a shift from the long, linear supply chain, economies of scale and centralisation tendencies, towards more distributed production models (Srai et al., 2016). The user interface is also changing, with the blurring of the boundary between consumers and producers leading to higher product personalisation and customisation.

At the firm level, DM comprises a category of manufacturing systems characterised by autonomy, flexibility, adaptability, agility and decentralisation (Leitao, 2009). At the economy level, DM fits into distributed economies that feature different regions pursuing different innovative development strategies according to local needs and further characterised by flexible networks of diverse actors (Kohtala, 2015). Srai et al. (2016) identified the following major characteristics of distributed manufacturing based on a cross-case analysis done on different sectors:

Digitalisation: A relatively new, pervasive and disruptive phenomenon in manufacturing which mainly permits a product to exist perpetually in a virtual form ready to be rendered at any time.

Localisation: Products can be potentially produced anywhere, and possibly nearer to the end-user, given the local availability of resources and access to new production technologies.

Enabling technologies: Technologies that can operate at a small scale and are agile. This permits their proliferation in many production sites with less restriction on where they might be located.

Personalisation: The enhanced interactive role for consumers resulting in better customisation of goods and services through collaborative production.

Distributed manufacturing systems (DMS) already provide several benefits in comparison to traditional centralised production concepts (Seidenstricker, Rauch \& Battistella, 2017). Megatrends such as sustainability, the democratisation of design, open innovation, regionalism and authenticity, and instant availability can be provided by DMS and drive the change to modern organisationally decentralised production (Matt, Rauch \& Dallasaga, 2015; Putnik et al., 2013). Seidenstricker et al. (2017) conclude that the connectivity and achievements in the IoT will drive forward the decentralised concepts and will enable other planning and control systems in manufacturing based on DMS thinking.

The United Nations Industrial Development Organization (UNIDO) and the World Economic Forum identified DMS among the key emerging trends in global manufacturing industries. In a website article, Top 10 Emerging Technologies 2015, 
Bernard Meyerson (2015) asserts that 'distributed manufacturing turns on its head the way we make and distribute products' by decentralising raw materials and fabrication and final products manufactured close to the final customer. The UNIDO report Emerging Trends in Global Manufacturing Industries argues that long-term industrial competitiveness may depend on countries' ability to build and upgrade production-related industrial capabilities and to address existing technology gaps. This would require African countries to develop their national manufacturing development strategies by taking into account emerging technologies and trends such as distributed manufacturing systems (UNIDO, 2013).

\section{Precursors of a distributed renewable economy}

Throughout human history, there have been communities that have been living in harmony with nature, albeit on a more subsistence basis. This was and still is the case with hunter-gatherer societies that utilise mobility as a critical regulating factor for their relationship with nature. The fundamental organising principle of these communities over the millennia has been to live within the limit of the carrying and assimilative capacity of their natural environment. This, however, started to change with the onset of the agricultural transformation, which resulted in a new set of property ownership and production systems. Except for a few cases that led to the downfall of major civilisation, the agricultural society mainly adhered to the overall principle of keeping within the limit of the carrying capacity. This is primarily due to the local nature of most of the environmental impact caused by the agricultural society and its limits within the assimilative and regenerative capacity of local ecosystems.

However, the localised nature of environmental impacts started to fundamentally change with the industrial revolution, which was based on the total disregard of the principle of living within the carrying capacity of nature and was driven by the desire to have complete control over natural systems. The drive for full domination and exploitation of nature, driven by unchecked industrialisation led to a significant depletion and degradation of the natural ecosystems that provide the necessary ecosystem services for the whole economy and society. This led to an unbearable situation in the second half of the twentieth century - a situation that gave governments in industrialised countries a wake-up call. The increasing scientific knowledge about the impact of industrialisation on the environment combined with the pressure from civil societies and the general public led to the convening of the Stockholm Conference on Human Environment in 1972. This was followed by the United Nations Conference on Environment and Development (UNCED) in 1992 as the environmental challenge became more of a global proportion. 
Since the adoption of Agenda 21 at UNCED in 1992, we have seen thousands of initiatives that were aimed at reconciling the environment and development goals at the local level. The following subsections consider some of these initiatives that could be considered as precursors for a distributed renewable economy.

\section{Sustainable communities}

This section covers the guiding principles of the numerous local initiatives on establishing sustainable communities as part of the implementation of Agenda 21 on sustainable development at the local level.

In general, sustainable communities are regarded as those communities that meet the economic needs of the community residents, enhance and protect their environment and promote more humane local societies. The main focus is on increasing local economic diversity that is self-reliant driven by the development of local markets, local production and greater cooperation among local economic entities. This is all coupled with an emphasis on reduction in the use of energy and the careful management and recycling of waste products (Oloyede, 2017). Over the last few decades, there have been thousands of local initiatives aimed at creating sustainable communities that strive to maintain harmony with their natural surrounds while at the same time promoting social inclusivity. Out of the many principles developed by different groups, the list that follows describes some of the key sustainable community development planning principles established by the South African Government, and in particular those in the Nelson Mandela Bay Municipal area (NMBM):

Poverty alleviation and satisfaction of basic needs with a particular focus on communities with special needs and gender equality is necessary for any planning intervention for sustainable community development.

Emphasising the environment as a planning principle involves incorporation of environmental aspects with the purpose of protection as well as sustainable utilisation and management of resources.

Publicparticipation is ageneral principle in planning that has specificsignificance at the sustainable community unit level. While the Spatial Development Framework deals with vision, long-term strategies and metro-level planning, sustainable community planning enable communities to participate in and influence planning for development in their area in concrete ways.

Local economic development is crucial to achieve improved living conditions and promote sustainability. At the sustainable communities' level, local economic development is particularly important as it contributes to local income earning, local markets and improvement of informal businesses. 
Mixed-use development is a planning principle that directly provides for functional and social integration. The location of different uses in proximity to each other facilitates access and promotes efficient urban development. It promotes sustainability through more efficient use of resources and infrastructure.

Variation and flexibility involve urban design aspects in the form of different types of housing, heights, densities and land use, and provision for different land tenure options within a community area. Furthermore, the principle allows for changes over time to accommodate a growing or shrinking households and alternative economic activities.

Limiting urban sprawl is closely linked to densification and creation of compact urban structures. It is, therefore, an essential aspect of integration and sustainability and crucial for efficient infrastructure provision.

\section{Smart urbanism}

Smart urbanism poses the view that the solution to building a better urban society lies in mobilising people's latent creativity. As an antidote to bigness, it looks to harness the collective power of many small, bottom-up ideas and actions to shape the urban neighbourhood. It is mainly guided by the principles of radical incrementalism, which is a deliberate strategy through which a series of small changes are enacted one after the other resulting in radical cumulative changes in the formation of a neighbourhood. It is iterative, and adaptive learning at its best as the feedback you get along the way will initiate, accelerate and modify next actions (Campbell, 2018). Based on insights and lessons gained from various local initiatives on urban development, Campbell (2018) further identified the following key principles:

We must shift our centralised system from its top-down, command-and-control process to operating in a more enabling role while at the same time dovetailing this with an evolving distributed system.

We need to embrace complexity and see the city in the context of a complex adaptive system rather than using traditional planning techniques that do not have the flexibility needed to address multifaceted and rapidly-paced urban change.

Urban design must be a generative process, from which a form will emerge and one that must incorporate the decisions and needs of local stakeholders not as a matter of fairness only but also of the intrinsic quality of the result. 
Urban neighbourhood development needs to shift from a 'bigness' model that is characterised by large-scale neighbourhood schemes that are driven by top-down capital accumulation to a 'massive small' model that is characterised by bottom-up land management model which promote diversity of provisions.

Putting the sustainability agenda which is guided by 'thinking globally while acting locally' together with the viability agenda, which is guided by 'thinking locally and acting locally', together gives a powerful signal across the full spectrum of local to global and enables the abstract model to work with an agent-based model for real difference.

\section{Regenerative economies}

Contrary to the conventional economic thinking, which presumes economic vigour as a function of the rate of gross national product growth, regenerative economies recognise 'economic vigour as a product of human and societal vitality, rooted in ecological health and the inclusive development of human capabilities and potential' (Fullerton, 2015:40). The following are the key and interconnected principles that determine systemic health under regenerative economies, as highlighted by Fullerton (2015:44-79):

In right relationship: Humanity is an integral part of an interconnected web of life in which there is no real separation between 'us' and 'it' and the scale of the human economy matters in relation to the biosphere in which it is embedded.

Views wealth holistically: Real wealth must be defined and managed in terms of the wellbeing of the whole, achieved through the harmonisation of multiple kinds of wealth or capital, including social, cultural, living and experiential. The whole is only as strong as the weakest link.

Innovative, adaptive, and responsive: In a world in which change is both everpresent and accelerating, the qualities of innovation and adaptability are critical to health. To use the Darwinian expression the most 'fit' is the one that is most adaptable to a changing environment.

Empowered participation: In an interdependent system, fitness comes from contributing in some way to the health of the whole. The quality of empowered participation means that all parts must be 'in a relationship' with the larger whole in ways that not only empower them to negotiate for their own needs but also enable them to add their unique contribution towards the health and well-being of the larger wholes in which they are embedded. 
Honours community and place: Each human community consists of a mosaic of peoples, traditions, beliefs and institutions uniquely shaped by long-term pressures of geography, human history, culture, local environment and changing human needs.

Edge effect abundance: Creativity and abundance flourish synergistically at the 'edges' of systems, where the bonds holding the dominant pattern in place are weakest. Working collaboratively across edges is transformative for both the communities and individuals involved.

Robust circulatory flow: Just as human health depends on the healthy circulation of oxygen and nutrients, so too does economic health depend on robust circulatory flows of money, information, resources, and goods and services to support exchange, flush toxins and nourish every cell at every level of our human networks.

Seeks balance: Being in balance is more than just an excellent way to be as it is essential to systemic health. A regenerative economy seeks to balance efficiency and resilience; collaboration and competition; diversity and coherence; and small, medium, and large organisations and needs.

The tens of thousands of local initiatives that have been developed and implemented across the globe under these and other similar initiatives have led to a massive volume of empirical knowledge on how to plan and implement bottomup initiatives that are driven by communities. African countries can gain valuable practical insights from these initiatives, which are also happening in their localities, and use them as a pilot basis for the development of distributed economy networks.

\section{Development of a distributed renewable economy}

Planning for a distributed renewable economy is aimed at creating a local, sustainable economy network as a foundation for developing a wellbeing economy that continuously fulfils the needs and aspirations of its people while ensuring the wellbeing of the natural ecosystem. Figure 7.1 presents the key development objectives of a wellbeing economy under human wellbeing and ecosystems wellbeing. The fundamental objective of the Wellbeing Economy in relation to human wellbeing is fulfilling the basic needs and aspirations of its people while continuously enhancing the productive capacity of the community. A wellbeing economy recognises that these fundamental objectives of human wellbeing could only be achieved by ensuring the wellbeing of the ecosystem which provides the primary ecosystem services input within the limits of its regenerative and assimilative capacity. 


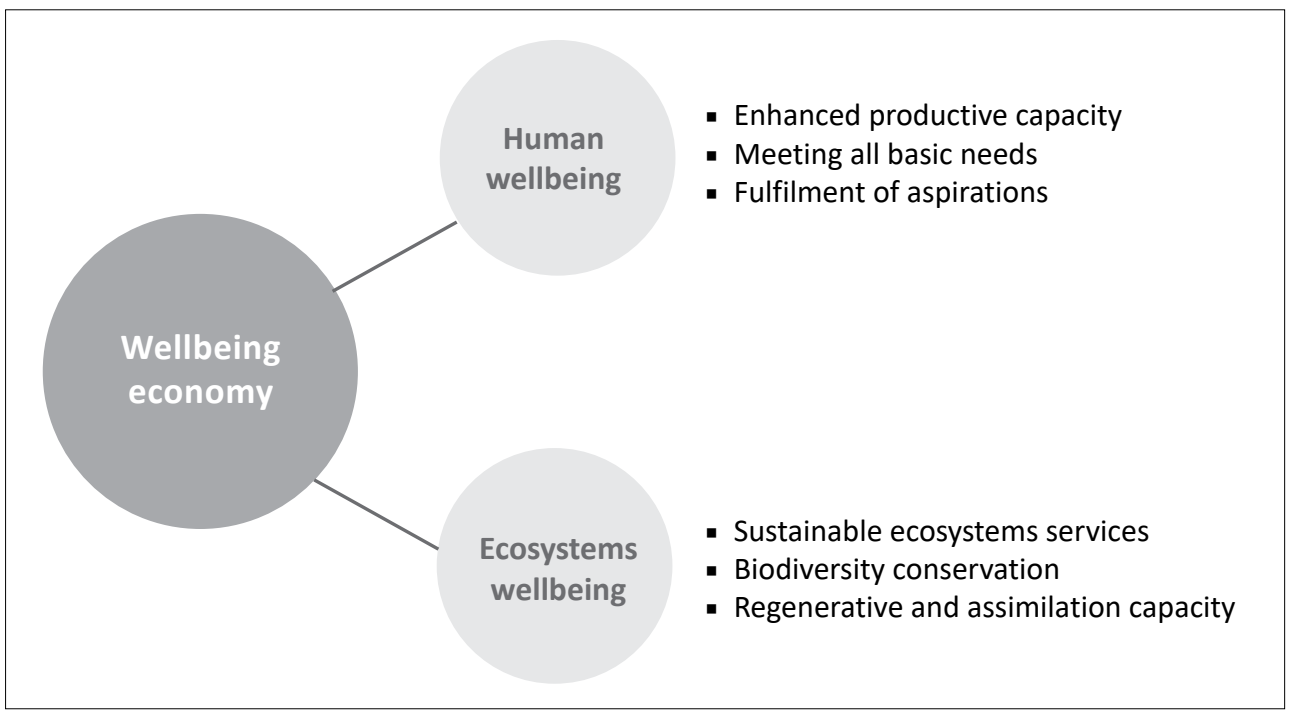

Figure 7.1 Key objectives of a wellbeing economy

Distributed renewable economy is a planning tool that will enable countries to reconcile the above two fundamental objectives at the local level. Based on case studies conducted in different countries, Van den Dool et al. (2009) identified the following as the potential benefits attributed to a distributed economy:

Increased local use of renewable resources and wealth creation for more people.

Decreased pollutant emissions and waste generation at the local and regional levels.

Added value benefits maintained within the region.

Increased share of non-material inputs (e.g., information, local know-how) and higher added value to local materials.

$\square$ Diversity and flexibility of economic activities and increased diversity and intensity of communication.

Enhanced collaboration between regional activities.

\section{The basis for a distributed renewable economy}

As noted by Fioramonti (2017), the shift towards quality jobs and distributed production and consumption require dismantling the vertical approach of the growth economy to support a horizontal network across an economy. The distributed renewable economy development model is about building the foundation for the transition to an inclusive, low-carbon and resource-efficient society through a 
bottom-up process that is built upon dynamic interaction between sustainable local economy networks. The following are the major theoretical and empirical premises that serve as the basis for the development of a distributed renewable economy:

The current dominant notion of economy of scale, which favours concentration and consolidation of the productive capacity of society around a limited number of players and actors, is fundamentally constrained to create a sufficient number of jobs and promote social inclusion as stated in Agenda 2030 on SDGs and the aspiration of Agenda 2063.

The significant progress made in the areas of renewable energy technology, information technology and distributed (modular) manufacturing systems in recent decades has also made the dominant economy of scale, which is characterised by large scale mass production, increasingly obsolete. This provides the basis for distributed economies consisted of dynamic local economic networks.

The enormous potential that African countries have in terms of renewable energy resources coupled with its natural resources provide a significant opportunity for African countries to develop more sustainable local economies that are mainly driven by distributed renewable energy systems.

As much as it may have its own threats, recent developments in ICT and the increasing digitisation of the global economy open new empowerment opportunities for African countries provided that they proactively manage and use them in a transformative way. The development of such local economy networks in the region would make a significant contribution towards job creation and value addition at the local level. This will, in turn, provide the basis for a profound social transformation towards a sustainable society.

Developing and promoting distributed renewable economies that are driven by distributed renewable energy systems which utilise the abundant renewable energy resource that Africa has, and maintaining the ecological foundation of African economies are fundamental for promoting economic development and social transformation in the region.

\section{Development framework for distributed renewable economy}

Distributed renewable economy is being developed as a planning model that reinforces the ongoing work of reorienting macro-economic policies at the national level with a bottom-up process that demonstrates the contribution of the development process to poverty eradication and sustainable development. As a planning tool, distributed renewable economy facilitates the operationalisation of the transition to a sustainable economy through efficient management and 
utilisation of the available resources within a given region or locality. As such, it does not come with a ready-made blueprint in the form of 'one-size-fits-all' approach. It instead provides a methodological framework to assist and guide local communities and development partners to develop and implement their own inclusive, low-carbon and resource-efficient economy which will dynamically evolve. It also provides an operational framework through which maximum synergy could be promoted between various initiatives aimed at promoting sustainable development and thereby promoting effective resource utilisation.

The distributed renewable economy process is guided by key systems and evolutionary principles of which the following could be cited as the major ones:

Incremental efficiency gains and systems innovation: The sustainability transition requires promoting incremental efficiency gains contributing to resource decoupling supported with broader systems innovation aimed at impact decoupling.

Technological innovation coupled with social innovation: The systems innovation that is required for the sustainability transition would require reinforcing the ongoing technological innovation with social innovation systems at all levels.

Self-organising systems through symbiotic relationships: The development of a more stable and sustainable economic system that operates as a selforganising socio-economic system following the principles of industrial symbiosis is at the core of a distributed renewable economy.

Adaptive and inclusive governance: The development and implementation of the distributed renewable economy at any level requires the innovative engagement of all sectors of the society guided by the principles of adaptive and inclusive governance.

Some fundamental shifts need to happen in the overall framing and implementation of the planning process to make progress in developing a distributed economy. Based on the above principles and the key concepts and empirical lessons covered in earlier sections, the following planning framework is proposed as a generic framework that could be modified and adapted to local contexts. As shown in Figure 7.2, the framework consists of three stages that have nine key steps altogether. 
Planning and

organising

Piloting and

implementing

Consolidating

and replicating
- Identify anchor natural resource sectors and economic actors

- Decide on specific value-addition products

- Organise innovation incubation space

- Determine resource inputs and develop infrastructure

- Develop first-tier economic networks

- Ensure horizontal and vertical integration within the network

- Facilitate optimal link with regional, national and global economy

- Monitor and recognise performances across network

- Plan for the second-tier of networks

Figure 7.2 Development framework for distributed renewable economy

The first stage of the framework covers the planning and organising steps as the foundation of the process. The crucial first step of the whole process is to identify a natural resource sector and or an economic actor which could be used as an anchor for the development of the distributed economy network. The next step is to organise an innovation incubation space to identify the specific economic activity that may lead to higher value addition and job creation for the local economy.

The second stage is the piloting and implementation stage which focuses on the actual development of the distributed economy network around the selected resource sector or economic actor. Depending on the level of preparedness and the possible success rate, this stage can start with a piloting phase to be followed with full-scale implementation. The critical step in this stage is the definition and development of the resource input required with a particular focus on the provision of energy, knowledge and financial inputs. This would require making the best use of the available knowledge, technological and financial resources that are highlighted in this section. The initial focus of this stage is on the development of the first tier of the economic network around the most promising resource and economic actors by ensuring an optimal vertical and horizontal integration across the value chain.

The third stage focuses on further consolidating and possibly replicating the economic network into a second tier of economic activities. The critical step in this stage is the facilitation of an optimal and efficient link of the local economic network with the national and global economic system. It is critical to continuously monitor the effectiveness of the economic actors in the network with the purpose of feeding back the lessons into the process and encourage competition by giving recognition to the best-performing actors and stakeholders.

Each of the steps in the development framework needs to be guided by the key principles highlighted in this section and supported by the relevant tools that are available in connection with local development planning processes. 


\section{Conclusion}

Creation of jobs to the youth population that is growing at an alarming rate, eradication of poverty, and gender empowerment are three of the most common and critical development priorities that are cited in almost all of the continental and national development visions, policies and strategies. Evidence from the past couple of decades has clearly shown that challenges of job creation and social inclusivity continued to be further aggravated across the world, but more severely in Africa. The fourth industrial revolution, driven by inappropriate application and utilisation of exponentially disruptive technologies is feared to increase the number of vulnerable jobs by putting more people out of jobs. It is also expected to widen the wealth gap significantly by further reinforcing the concentration of wealth in few hands. Fortunately, most of the disruptive technologies of the twenty-first century also have significant potential to promote distributional justice by empowering people and enhancing the overall socio-ecological efficiency of the global economic system.

One of the major areas where the disruptive technologies of the twenty-first century would have significant transformation outcomes is in the field of promoting distributed economy networks that are aimed at creating more jobs and adding multiple values at the local level. Even if this could apply to almost all countries, Africa has a unique opportunity to gain the maximum benefit from such a strategic approach. A systematic application of distributed economy networks development could also assist countries to overcome the limitation and save wastage from the fragmented and isolated implementation of development programmes, which is an Achilles heel of most development programmes in African countries. Finally, it is worth noting that an Africa that is at peace with itself and with its natural environment; an Africa that is inclusive, low-carbon and resource-efficient; and an Africa that is free of poverty and unemployment makes a critical contribution to global security and sustainability. Supporting the proliferation of distributed economy networks across the region is one sure way of achieving the Africa We Want' of Agenda 2063 and the 'Future We Want' of Agenda 2030. 


\section{References}

Alanne, K. \& Saari, A. (2006). Distributed energy generation and sustainable development. Renewable and Sustainable Energy Reviews 10(6): 539-558. https:// doi.org/10.1016/j.rser.2004.11.004

Ayres, R.U. (1994). Information, entropy, and progress: A new evolutionary paradigm. New York: American Institute of Physics Press.

Baran, P. (1964). On distributed communications network. Reprinted from the IEEE Transactions on Communications Systems CS-12(1), March. https://bit.ly/2MamttJ [Accessed 20 September 2019]. https://doi. org/10.1109/TCOM.1964.1088883

Bauwens, M. \& Kostakis, V. (2015). Towards a new reconfiguration among the state, civil society and the market. https://bit. ly/2B666b9 [Accessed 24 May 2018]. https://doi.org/10.21721/p2p.2014v1 n1.p1-24

Breda, J.V. \& Swilling, M. (2018). The guiding logic and principles for designing emergent transdisciplinary research processes. Sustainability Science 13(42): 1-19. https://doi.org/10.1007/s11625-0180606-x

Campbell, K. (2018). Making massive small change: Building the urban society we want. London: Chelsea Green Publishing.

Cooper, M. (2016). Renewables and distributed resources in a post-Paris low carbon future: The key role and political economy of sustainable electricity. Energy Research \& Social Science 19: 66-93. https://doi.org/10.1016/j.erss.2016.05.008

Dafermos, G. (2015). Transforming the productive base of the economy through the open design commons and distributed manufacturing. https://bit.ly/2B743DC [Accessed 16 May 2016].

Fioramonti, L. (2017). Wellbeing economy: Success in a world without growth. Johannesburg: Macmillan.
Fischer-Kowalski, M. \& Harbel, H. (2007). Socioecological transitions and global change: Trajectories of social metabolism and land use. Cheltenham, UK: Edward Elgar Publishing. https://doi. org/10.4337/9781847209436

Fullerton, J. (2015). Regenerative capitalism: How universal principles and patterns will shape our new economy. https://bit.ly/1bDuUrY [Accessed 15 September 2019].

Genov, N. (1999). Managing transformations in Eastern Europe. Paris: UNESCO-MOST.

Gottlieb, R.S. (Ed.). (1996). This Sacred earth: Religion, nature and environment. New York: Routledge.

International Energy Agency. (2014). Africa energy outlook. Paris: IEA. https://doi. org/10.1787/weo-2014-en

International Renewable Energy Agency. (2013). Africa's renewable future: The path to sustainable growth. Abu Dhabi, UAE: IRENA. https://doi. org/10.4324/9781315074436

International Renewable Energy Agency. (2015). Africa 2030: A roadmap for renewable energy future. Abu Dhabi, UAE: IRENA.

Johansson, A., Kisch, P. \& Mirata, M. (2005). Distributed economies - A new engine for innovation. Journal of Cleaner Production 3(10/11): 971-979. https://doi. org/10.1016/j.jclepro.2004.12.015

Kohtala, C. (2015). Addressing sustainability in research on distributed production: An integrated literature review. Journal of Cleaner Production 106(1): 654-668. https://doi.org/10.1016/j. jclepro.2014.09.039

Kosko, B. (1994). Fuzzy thinking: The new science of fuzzy logic. London: Flamingo Publishers. 
Leitao, P. (2009). Agent-based distributed manufacturing control: A state-of-the-art survey. Engineering Applications of Artificial Intelligence 22(7): 979-991. https://doi. org/10.1016/j.engappai.2008.09.005

Leroy, P. (1997). Interdisciplinarity within Dutch environmental science(s). Proceedings of the Conference on Science for Sustainability: Integrating Natural and Social Sciences. Roskilde: Roskilde University.

Lorenzo, F. (2017). Wellbeing economy: Success in a world without growth. Johannesburg: Macmillan.

Matt, D.T., Rauch E. \& Dallasaga, P. (2015). Trends towards distributed manufacturing systems and modern forms for their design. Procedia CIRP 33: 185-190. https://doi. org/10.1016/j.procir.2015.06.034

McClaughry, J. (1989). Preface. In: E.F. Schumacher, Small is beautiful. London: Harper Perennial.

Meadows, D., Meadows, D. \& Randers, J. (1992). Beyond the limits (1st edition). London: Chelsea Green Publishing.

Mebratu, D. (1998). Sustainability and sustainable development: Historical and conceptual review. Environmental Impact Assessment Review 18(6): 493-520. https:// doi.org/10.1016/S0195-9255(98)00019-5

Mebratu, D. (2000). Strategies for sustainable industrial development in sub-Saharan Africa. Lund, Sweden: Lund University.

Meyerson, B. (2015). Top 10 emerging technologies of 2015. https://www. weforum.org/agenda/2015/03/top10-emerging-technologies-of-2015-2/ \{Accessed 20 September 2019].

Miller, T.R., Wiek, A., Sarewitz, D., Robinson, J., Olsson, L. et al. (2014). The future of sustainability science: A solutionsoriented research agenda. Sustainability Science 9(2): 239-246. https://doi. org/10.1007/s11625-013-0228-2

Mundaca, L., Markandya, A. \& Nørgaard, J. (2013). Walking away from a low carbon economy? Recent and historical trends using a regional decomposition analysis. Energy Policy 61: 1471-1480. https://doi. org/10.1016/j.enpol.2013.04.083

Nelson Mandela Bay Municipality. (2007). Sustainable community planning guide. https://bit.ly/2B8aXZe [Accessed 10 September 2019].

Oloyede, O. (2009) Developing sustainable communities in Africa: Components for a Framework. Identity, Culture and Politics: An Afro-Asian Dialogue 10(2): 56-64. https://bit.ly/316iZww [Accessed 2 May 2017].

Putnik, G., Sluga, A., Elmaraghy H., Teti, R., Koren, Y. et al. (2013). Scalability in manufacturing systems design and operation: State of the art and future developments roadmap. CIRP Annals Manufacturing Technology 62(2): 751-774. https://doi.org/10.1016/j.cirp.2013.05.002

Raji, A. \& Kahn, M.T. (2012). Analysis of distributed energy resources for domestic electricity users. Journal of Energy in Southern Africa 23(2): 50-55. https:// doi.org/10.17159/2413-3051/2012/ v23i2a3163

REN21. (2017). Renewables 2017 global status report. Paris: REN21 Secretariat.

Roszak, T. (1989). Introduction. In: E.F. Schumacher, Small is beautiful. New York: Harper Perennial.

Scholz, R.W. (2011. Environmental literacy in science and society: From knowledge to decisions. Cambridge, UK: Cambridge University Press. https://doi.org/10.1017/ CBO9780511921520

Schwab, K. (2018). Shaping the fourth industrial revolution. Geneva: World Economic Forum.

Seidenstricker, S., Rauch, E., \& Battistella, C. (2017). Business model engineering for distributed manufacturing systems. Procedia CIRP 62: 135-140. https://doi. org/10.1016/j.procir.2016.06.112 
Seidl, R., Brand, F.S., Stauffacher, M., Krütli, P., Le, Q.B. et al. (2013). Science with society in the anthropocene. Ambio 42(1): 5-12. https://doi.org/10.1007/s13280-0120363-5

Smuts, J. (1993). Holism and evolution. In: J.J. Clarke (Ed.), Nature in question: An anthology of ideas. London: Earthscan Publications.

Srai, J.S., Mukesh, K., Graham, G., Philips, W., Tooze, J. et al. (2016). Distributed manufacturing: scope, challenges and opportunities. International Journal of Production Research 54(23): 6917-6935. https://doi.org/10.1080/00207543.2016. 1192302

Stauffacher, M., Walter, A.I., Lang, D.J., Wiek, A. \& Scholz, R.W. (2006). Learning to research environmental problems from a functional socio-cultural constructivism perspective: The transdisciplinary case study approach. International Journal of Sustainability in Higher Education 7(3): 252-275. https://doi. org/10.1108/14676370610677838

Swilling, M. \& Annecke, E. (2012). Just transitions: Explorations of sustainability in an unfair world. Tokyo: United Nations University.
United Nations Industrial Development Organization. (2013). Emerging trends in global manufacturing industries. Vienna: UNIDO.

van den Dool, A., Marchington, E., Ripken, R., Hsieh, A., Petrasova, M. et al. (2009). The future is distributed: A vision for sustainable economies. Lund, Sweden: Lund University.

Vázquez Pimentel, D.A., Ayma, I.M. \& Lawson, M. (2018). Reward work not wealth. Oxfam Briefing paper, January. Cowley, UK: Oxfam GB. https://bit. ly/2q8ejcD [Accessed 13 March 2019].

Weinberg, M.G. (1975). An introduction to general systems thinking. New York: Wiley-Interscience Publications. https:// doi.org/10.1080/03081077508960832

Wiek, A. \& Lang, D.J. (2016). Transformational sustainability research methodology. In: H. Heinrichs, P. Martens, G. Michelsen \& A. Wiek (Eds), Sustainability science. Dordrecht, Netherlands: Springer. https://doi. org/10.1007/978-94-017-7242-6_3

Ziegler, H. (1997). Statement at the final panel of the conference. Conference of Science for Sustainability: Integrating Natural and Social Sciences. Roskilde University, Denmark (October). 